\title{
Effect of Hydrothermal Pretreatment for Enhanced Biogas Production Using Micro-algal Biomass
}

\author{
Kwanyong Lee ${ }^{1}$, Daegi Kim², Ki Young Park ${ }^{3}$, Hyundong Lee ${ }^{1,4}$, and Chorong \\ $\mathrm{Kim}^{1}$ \\ ${ }^{1}$ Korea Institute of Civil Engineering and Building Technology, Environment and \\ Plant Engineering Research Institute, 283, Goyang-daero, Ilsanseo-gu, Goynang- \\ si, Gyeonggi-do,10223, Republic of Korea \\ ${ }^{2}$ Institute for Advanced Engineering, Plant Engineering Center, 175-28, Goan-ro, \\ 51 beon-gil, Baegam-myeon, Cheoin-gu, Yongin-si, Gyeonggi-do, 17180, Republic \\ of Korea \\ ${ }^{3}$ Konkuk University, Civil and Environmental Plant Engineering 120, Neungdong- \\ ro, Gwangjin-gu, Seoul, 05029 Republic of Korea \\ ${ }^{4}$ Unvierstiy of Science and Technology, Construction and Environment \\ Engineering 217, Gajeong-ro, Yuseong-gu, Daejeon, 34113, Republic of Korea \\ ${ }^{1}$ kwanyonglee@kict.re.kr, ${ }^{2}$ daegi.kim81@iae.re.kr, ${ }^{3}$ kypark@konkuk.ac.kr, \\ 1,4hdlee@kict.re.kr, ${ }^{1}$ crkim13@kict.re.kr
}

\begin{abstract}
The filamentous algal biomass, Hydrodictyon reticulatum (H. reticuatum) was used to evaluate the biogas production after hydrothermal pretreatment in batch anaerobic digestion. The effect of hydrothermal pretreatment at range of $50 \sim 280{ }^{\circ} \mathrm{C}$ was tested with filamentous algal biomass. The solubilization by pretreatment showed a higher degree of disintegrated filamentous algal biomass and the soluble COD was increased 12.8 fold than untreated sample at $280{ }^{\circ} \mathrm{C}$. Solubilization due to hydrothermal pretreatment increased the specific biogas production and volatile solids reduction rates. Using the hydrothermal treatment approach, the specific methane production were 161.8, 169.1, 178.4, 191.7, 274.9, 285.2 and $364.4 \mathrm{~mL} / \mathrm{g}$-VS of the pretreated at raw, 50, 100, $120,180,230$, and $280{ }^{\circ} \mathrm{C}$, respectively. The volatile solids reduction was greater with increased temperature applied, and the degradation increased $69.7 \%$ at $280{ }^{\circ} \mathrm{C}$ from 45.8 $\%$ VS reduction of raw filamentous algal biomass.
\end{abstract}

Keywords: We would like to encourage you to list your keywords in this section

\section{Introduction}

Recently, there has been increasing interest in assessing the energy potential of biofuels obtained from micro-algae (González-Fernández et al., 2011). Algae biofuels are an attractive option (Sigh et al., 2011) due to its rapid growth rate comparatively, low land usage and high carbon dioxide (Jorquera et al., 2010). Because of the other resource of biomass energy resources such as derived from terrestrial crops (first generation) and derived from lignocellulosic crops (second generation) were included the needs of arable land, large amount of water and low biomass productivities (González-Fernández et al., 2012). However, microalgae as a third generation of biomass resource based of biofuels are good materials to overcome the mentioned problems. Up to now, numbers of studies have been published to investigate the utilization of microalgae to produce of biodiesel, bioethanol and biohyderogen as a feedstock (Guldhe et al., 2014; Ho et al., 2013; Zhu et al., 2014). However, biofuel production from microalgae feedstock has several problems to be 
resolved before it can become an economical and environmental ways of alternative energy (Ward et al., 2014). The problems face high energy required for conversion process and the process of disposing the residual biomass is difficult even after beneficial lipid extraction since the defatted biomass still contains higher levels of organic matter, such as carbohydrate and protein (Park et al., 2013). Anaerobic digestion can be a solution to these problems because this technical process can mineralize algal biomass (Sialve et al., 2009). Biogas production from algae by anaerobic digestion is one of the most environmental and beneficial technology (Lee et al., 2014). However, anaerobic digestion of microalgae is limited by lard cell wall (Chen et al., 1998). According to the report of Golueke et al. (1957) digested sludge provided a noticeable green color during anaerobic digestion because of the persistence of chlorophyll, which in an intracellular material. This result showed that cellular lysis was not completed during digestion. Therefore, pretreatment of the algal biomass is needed because the complex cell wall structure of microalgae, composed by cellulose, hemicellulose and pectin, makes bacteria to attack difficult (Passos et al., 2013). González-Fernández et al, (2012) studied that comparison of ultrasound and thermal pretreatment of micro algal biomass to enhance the biogas production. Passos et al., (2013) employed microwave and thermal treatment to improve the disintegration and digestibility of microalgae. Hydrothermal pretreatment of lignocellulosic biomass was usually evaluated for enhanced bioethanol production (Kumar et al., 2009; Mood et al., 2013). Because the advantages of hydrothermal pretreatment for lignocellulosic biomass are no addition, hydrate cellulose, and remove hemicellulose and part of lignin (Chandra et al., 2012). However, little information is available regarding filamentous algal biomass of hydrothermal pretreatment for anaerobic digestion.

The objective of this study was to investigate the solubilization of filamentous alga, Hydrodictyon reticulatum ( $H$. reticulatum) using hydrothermal pretreatment. An additional aim of this work was to study the effects of different temperature for pretreatment to algal feed on anaerobic digestion

\section{Materials and Methods}

\subsection{Hydrothermal Pretreatment of Filamentous Algal Biomass}

The filamentous alga used in this study, $\mathrm{H}$. reticulatum, was supplied by the Korean Research Institute of Chemical Technology in Daejeon, Korea, and the characteristics of filamentous algal biomass presented in Table 1. The hydrothermal reactor was used to investigate the effect of hydrothermal pretreatment on the biogas improvement property and dewatering performance of the filamentous algal biomass, $H$. reticulatum. Experiments were performed using a $1000 \mathrm{~mL}$ autoclave reactor consisting of a reactor body, a heater, and a steam condenser which was operated under $\mathrm{N}_{2}$ gas. A $100 \mathrm{~mL}$ of $H$. reticulatum feed stock was mixed with an equal amount of water and leaded into the reactor. The operating temperatures and pressures ranged from 50 to 280 and the reaction time was 30 min. Typically the temperature was from 180 to 320 that present subcritical water. The components within the reactor were vigorously mixed using an agitator rotating at $200 \mathrm{rpm}$.

Soluble COD (SCOD) release was used as a direct measurement of filamentous algal biomass cell disintegration. When the filamentous algal biomass was pretreated by hydrothermal equipment, the intracellular contents were released in the aqueous phase. Increased SCOD after pretreatment was an indicator of the solubilization efficiency. All samples for SCOD were filtered through a $0.45 \mu \mathrm{m}$ membrane and then used for measurement. 
Table 1. Characteristics of Filamentous Algal Biomass

\begin{tabular}{c|c|c|c|c|c|c}
\hline & SCOD & $\mathrm{NH}_{3}-\mathrm{N}$ & $\mathrm{T}-\mathrm{N}$ & $\mathrm{TS}$ & $\mathrm{VS}$ & $\mathrm{VS} / \mathrm{TS}$ \\
\hline $\begin{array}{c}\text { Concentration } \\
(\mathrm{mg} / \mathrm{L})\end{array}$ & 44.45 & 2.70 & 140.00 & 5,860 & 5,330 & 0.91 \\
\hline
\end{tabular}

\subsection{Biochemical Methane Potential (BMP) Test}

Batch digestion was performed in a series of BMP assays by incubating algal biomass inoculated with anaerobic bacteria for a period about 35 days based on Angelidaki et al. (2009). The active inoculum operating at methophilic conditions was obtained from the anaerobic digester at the Jungrang municipal wastewater treatment plant in Seoul, Korea.

Two rounds of batch experiments were conducted under mesophilic conditions. The first round focused on the effect of Substrate to inoculums ratio (S/I ratio). The second round compared the biogas productivity and VSR depending on the different temperature of pretreatment. Batch anaerobic digestion was performed in $160 \mathrm{ml}$ serum bottles with a working volume of $100 \mathrm{ml}$. The data for both cumulative gas production and volatile solids reduction (VS reduction) were obtained during the digestion.

A nutrient/mineral/buffer (NMB) medium prepared according to Young and Tabak (1993). Duplicate units of the digestion setup were used for all pretreatment schemes in this research. Biogas production from inoculums and medium was recorded and used as the control. Substrate and inoculum were used at a ratio of 0.5:1 using the VS mass except the $\mathrm{S} / \mathrm{I}$ ratio experiment.

\subsection{Analytical Methods}

The concentration of Total Solid (TS), Volatile Solid (VS), Total Nitrogen (TN), Total Phosphate (TP), ammonia nitrogen, and COD were analyzed according to the standard methods (APHA, 2005). Total COD (TCOD) and Soluble COD (SCOD) were determined for solubility of filamentous micro algal biomass. The samples were centrifuged at $4000 \mathrm{rpm}$ for 5 min and the supernatant was filtered through a $4.5 \mu \mathrm{m}$ pore size membrane filter and then used for the analysis of SCOD. Biogas composition was determined by gas chromatography (Young Lin instrument 6800 series, Korea) using a thermal conductivity detector, by injecting gas samples into a packed column (hayeSep $3 \mathrm{~m} \mathrm{1/8}$ in. 100/120). The carrier gas was Helium in split less mode (column flow: $19 \mathrm{~mL} / \mathrm{min}$ ). The oven temperature was $35{ }^{\circ} \mathrm{C}$ with a retention time of $1.5 \mathrm{~min}$. Injector and detector temperatures were 150 and $180{ }^{\circ} \mathrm{C}$, respectively. The gas composition was measured toward the end of the experiment.

\section{Results and Discussion}

\subsection{Substrate to Inoculum Ratio Test}

The maximum methane productivity and the higher rate of methane productivity were reached at a S/I ratio of 0.5 , regardless of the filamentous algal biomass tested (Figure 1). At the different S/I ratios, the final methane productivity were 163.6, 137.9, 118.5 and $105.8 \mathrm{~mL} / \mathrm{g}-\mathrm{VS}$ for S/I ratios of $0.5,1.0,3.0$ and 5.0, respectively. Eskicioglu and Ghorbani (2011) published that the specific biogas production rate in BMP tests significantly decreased with decreasing inoculums to substrate ratio (ISR). They observed that all BMP tests had similar specific methane yields at the end of experiment. In other words, ISR did not affect the ultimate biodegradability of corn whole stillage. However, in case of the report by Zheng et 
al., (2010), the cumulative biogas production at the end of digestion for the ISR value of 2.0, 1.0 and 0.5 were 70.38, 126.57 and $153.51 \mathrm{~mL}$, respectively. Thus, the biogas production was depended on the substrate concentration or ISR. Because of the low ISR $(0.46, \mathrm{w} / \mathrm{w})$ accumulated high concentration of total volatile fatty acids and $\mathrm{pH}$ decreased during the batch anaerobic digestion reaction (Eskicioglu et al., 2011). In this study, we adopted the substrate to inoculums ratio of 0.5 (w/w) for the filamentous algal biomass methane production experiment belong to different temperature of pretreatment.

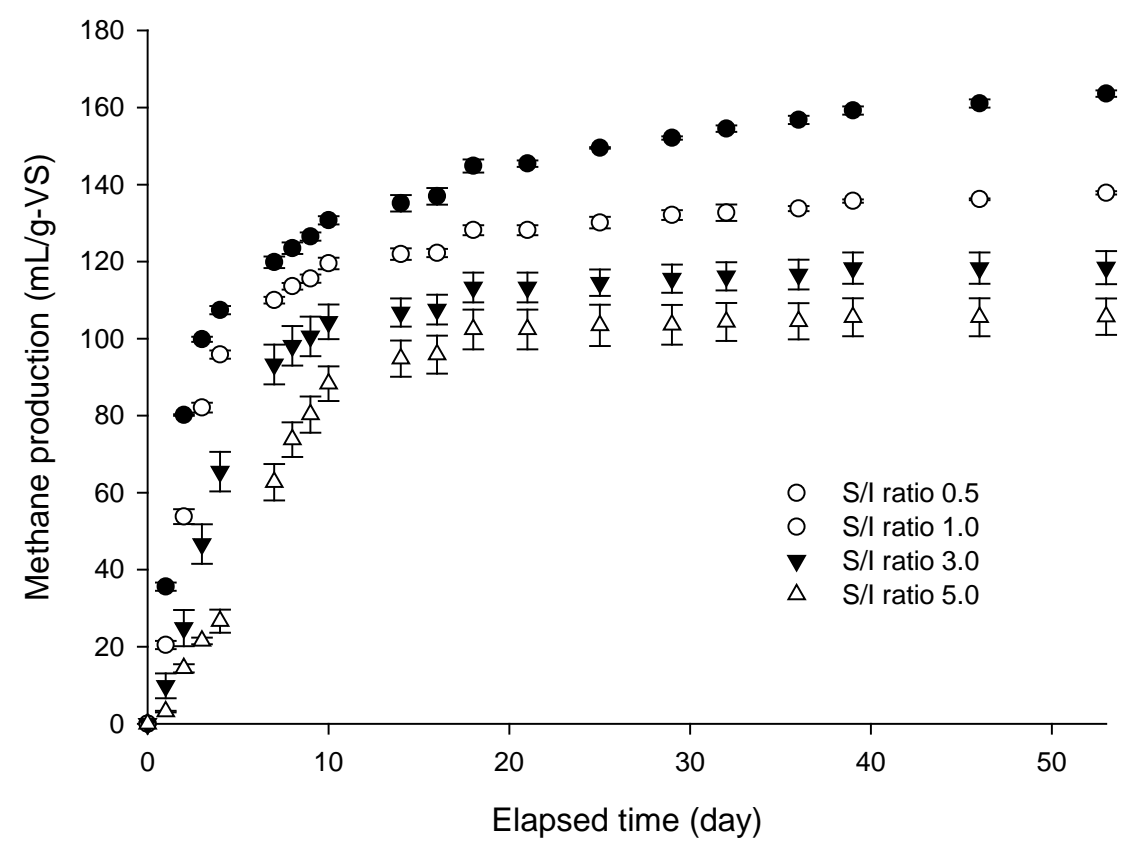

\section{Figure 1. Methane Production of Depending on the Substrate to Inoculum Ratio in Batch Anaerobic Digestion}

\subsection{Solubilization of Filamentous Algal Biomass}

Hydrothermal pretreatment focused on filamentous algal biomass to improve anaerobic digestion in this study. The biomass was subjected to hydrothermal pretreatment with the six different pretreatment temperatures. Two ranges of thermal pretreatment for anaerobic digestion batch experiments were conducted under mesophilic conditions. The first range was typical thermal pretreatment as 50 , 100 and $120{ }^{\circ} \mathrm{C}$, and the second was hydrothermal pretreatment range as 180, 230 and $280{ }^{\circ} \mathrm{C}$. Typically the temperature was from 180 to $230{ }^{\circ} \mathrm{C}$ that present subcritical waster. SCOD increased along pretreatment temperatures. GonzálezFernández et al (2012) assumed that thermal decomposition of organic material happened in several stages and the solubilization of organic matter belong to the pretreatment time at mild pretreatment temperatures such as 70 and $90{ }^{\circ} \mathrm{C}$. However, pretreatment temperature is more important than reaction time of solubilization for the organic sludge at the high temperature of pretreatment such as 175 to $200{ }^{\circ} \mathrm{C}$ (Haug et al., 1978). As it can be seen in Figure 2, TCOD was as decreased as SCOD increased. At the end of pretreatment time, $30 \mathrm{~min}$, SCOD increased by 5.3, 5.1, 5.3, 7.3, 11.8 and 12.8 fold for $50,100,120,180,230$ and $280{ }^{\circ} \mathrm{C}$ pretreated temperature, respectively. The results of solubilization in this study obtained similar with Keymer et al. (2013) report. They used high temperature and pressure to improve bio gas production of microalgae in anaerobic digestion. The algae biomass and lipid extracted algae fed in high temperature pretreatment equipment during 
about 30 min for solubilization of algae biomass and lipid extracted algae. The reaction temperature was $170{ }^{\circ} \mathrm{C}$. After pretreatment, high pressure thermal hydrolysis after lipid extracted of algae sample increased 10 fold of SCOD. Thus the hydrothermal pretreatment is expected particularly effective method at solubilization of organic materials (Wilson and Novak, 2009).

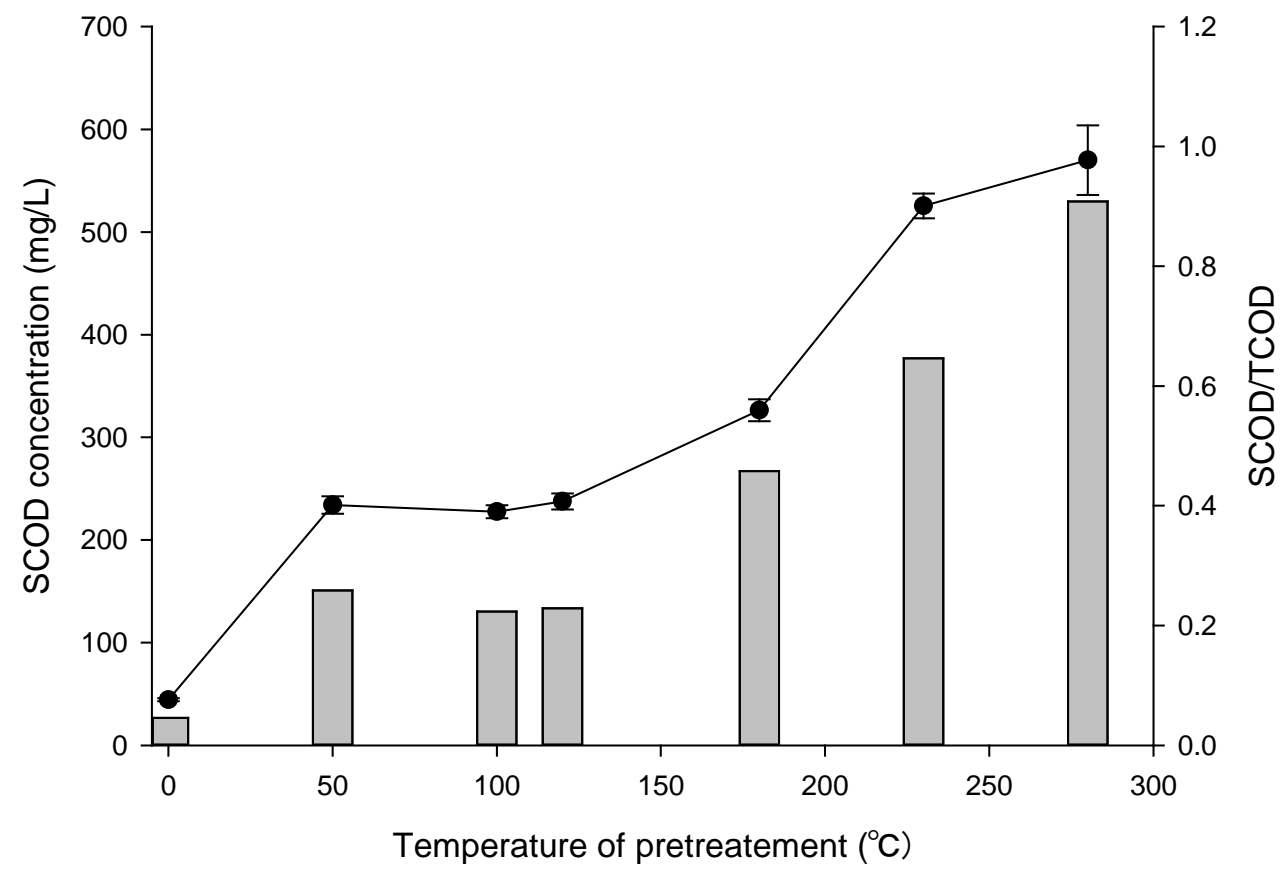

\section{Figure 2. Solubilization of Algal Biomass along Different Pretreatment Temperature}

\subsection{Effect of Pretreatment for Biogas Production}

The assessment of raw and pretreated algal biomass as substrate for the anaerobic digestion was evaluated by the BMP test over a period of 35 days (Figure 3). BMP assay were conducted to determine the specific conditions required for optimal methane production of algal biomass using different pretreatment temperature from 50 to $280{ }^{\circ} \mathrm{C}$. The filamentous algal biomass, $H$. reticulatum, was subjected to thermal pretreatment of different temperatures before the BMP assays. Methane production rate of all kinds of substrates was maximal during the first 8 days and decreased after that. Raw $H$. reticulatum substrate produced methane yield on VS basis of $161.8 \mathrm{~mL} / \mathrm{g}-\mathrm{VS}$ whereas pretreated samples at 50,100,120,180, 230, and $280{ }^{\circ} \mathrm{C}$ resulted in 169.1, 178.4, 191.7, 274.9, 285.2, and $364.4 \mathrm{~mL} / \mathrm{g}-\mathrm{VS}$, respectively. According to the previous study of Chen and Oswald (1998), methane production of algal was increased up to $33 \%$ at applied $110{ }^{\circ} \mathrm{C}$ pretreatment temperature for $8 \mathrm{~h}$. However, another researcher, De Schamphelaire and Verstraete (2009) reported that pretreatment of mixing microalgae was not effective to increase biogas at $80{ }^{\circ} \mathrm{C}$ for 2.5h. González-Fernández et al. (2012) reported that the thermally treated microalgae biomass showed a different behavior depending on temperature applied.

To compare the methane production of digestion of different pretreatment temperatures, according Fig. 3, there are two kinds of patterns depending on the temperatures of pretreatment. The first pattern of low temperature range (50 100 ${ }^{\circ} \mathrm{C}$ ) was appeared low methane production increasing rate $\left(10.27 \%\right.$ at $\left.100{ }^{\circ} \mathrm{C}\right)$. The second pattern of high temperature range $\left(120 \sim 280{ }^{\circ} \mathrm{C}\right)$ was reached about $125 \%$ at $280{ }^{\circ} \mathrm{C}$ of raw $H$. reticualtum biogas production. Thus, low temperature (50 120 
${ }^{\circ} \mathrm{C}$ ) pretreatment applying to enhance biogas production was not effective. However, when was applied high temperature $\left(180 \sim 280{ }^{\circ} \mathrm{C}\right)$ to increase methane production, it increased depending on the temperature rising (Figure 4). In other words, hydrothermal pretreatment was effective to improve methane production in anaerobic digestion condition. The results of methane production depending on different temperatures were similar with solubilization of filamentous algal biomass (Figure 3).

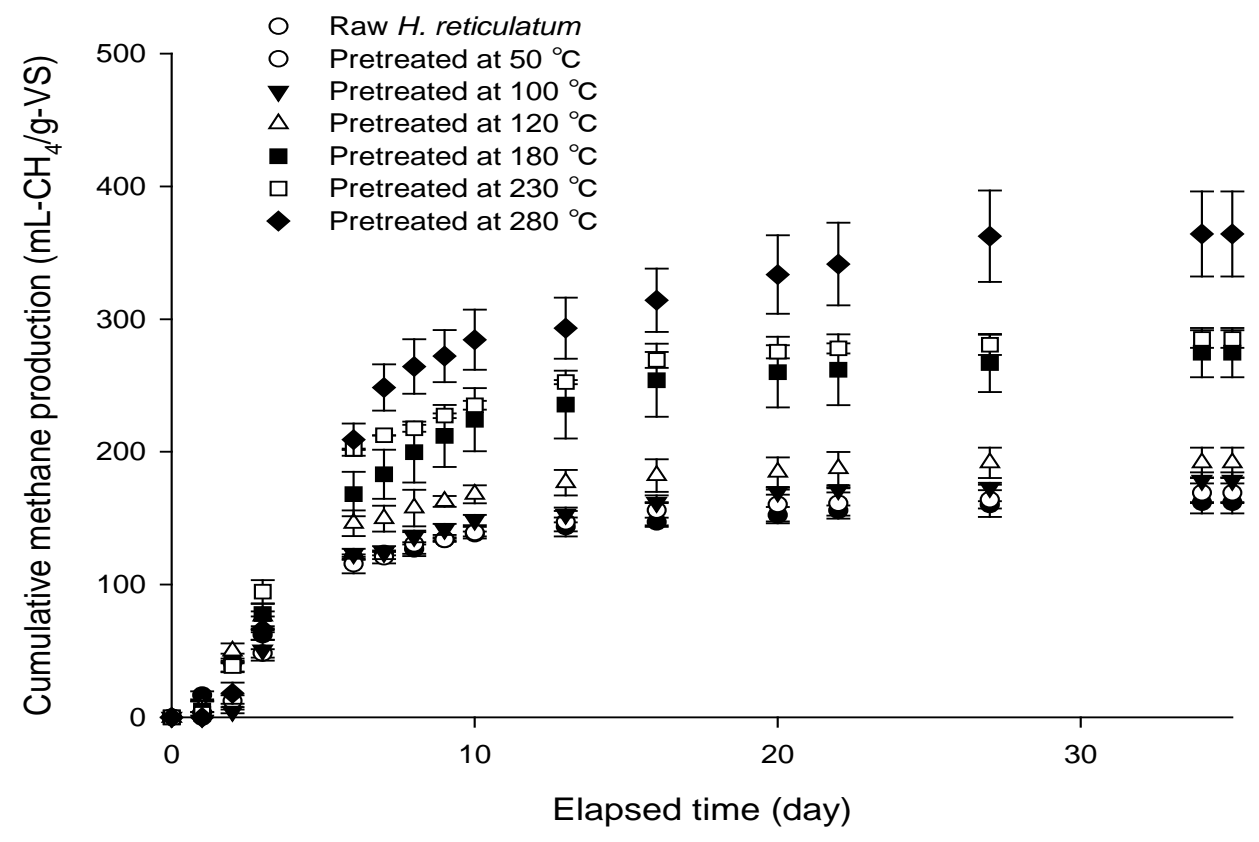

Figure 3. Methane Production of Algal Biomass depending on Pretreatment Temperature

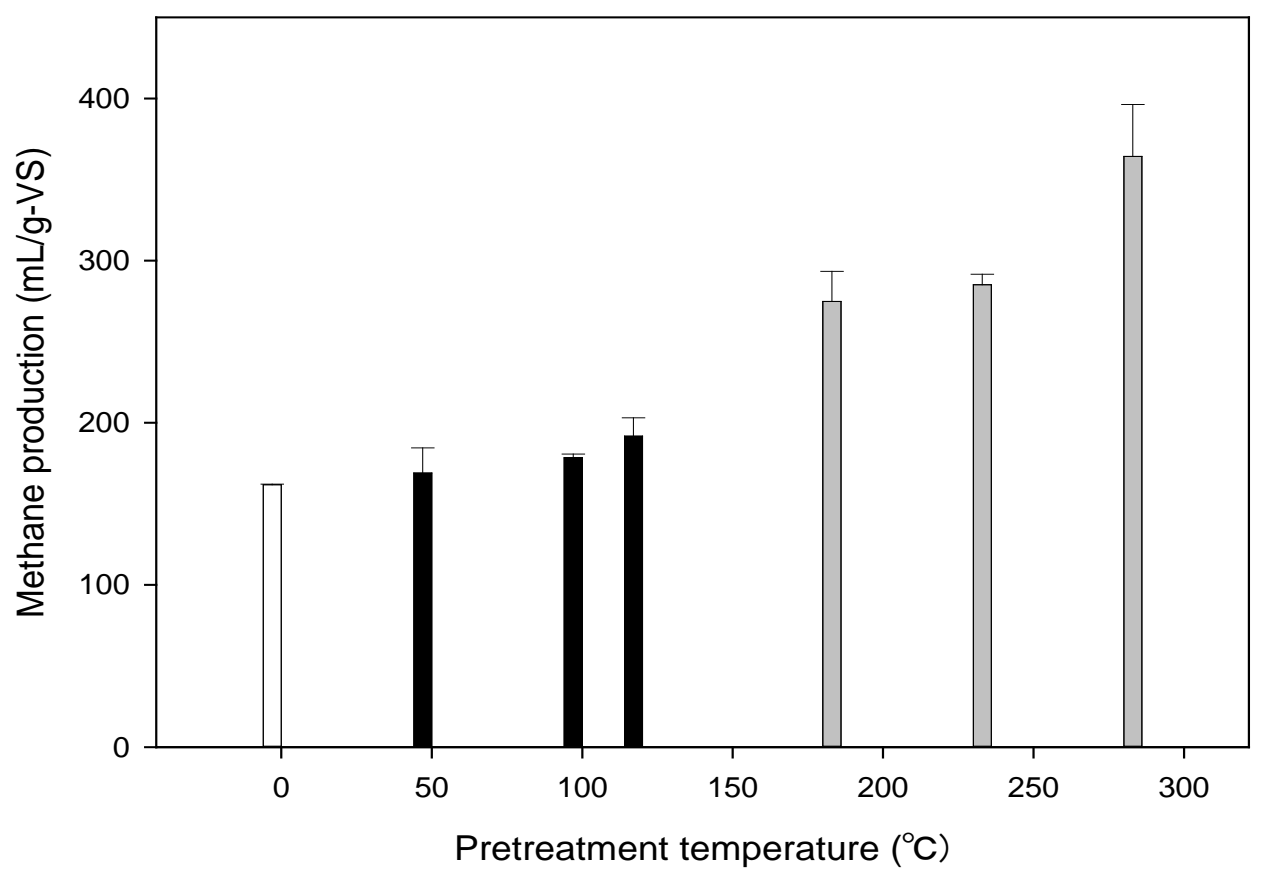

Figure 4. Methane Production Depending on Pretreatment Temperatures at the End of Experiment 


\subsection{Volatile Solids Reduction (VSR)}

Figure 5 shows the VS reduction versus the thermal pretreatment temperatures. VS reduction is an important parameter for assessment of biodegradation of organic matters. The results of the VS reduction after anaerobic digestion batch test were achieved 45.8, 54.4, 57.5, 61.7, 66.6, 68.0 and $69.7 \%$ with the applying pretreatment temperatures at raw, $50,100,120,180,230$ and $280{ }^{\circ} \mathrm{C}$, respectively. The VS reduction was increased with depending on the temperatures of pretreatment increasing only except at $280{ }^{\circ} \mathrm{C}$. Elango et al., (2007) studied VS reduction using municipal solids waste (MSW) and domestic sewage of high strength effluent in the continuous anaerobic digestion. They obtained the results of VS reduction were 73 and $87 \%$ with only initial range and after the continuous feeding of substrate, respectively. The activities of anaerobic microorganisms increase with the increase of temperature, reflecting stable degradation of substrate (Elango et al., 2007). Ratanatamskul et al. (2014) reported VS reduction of food waste and sewage sludge. VS reduction of $68.9,53.8$ and $44.2 \%$ were achieved with the applying hydraulic retention time at 27, 22 and 19 days, respectively.

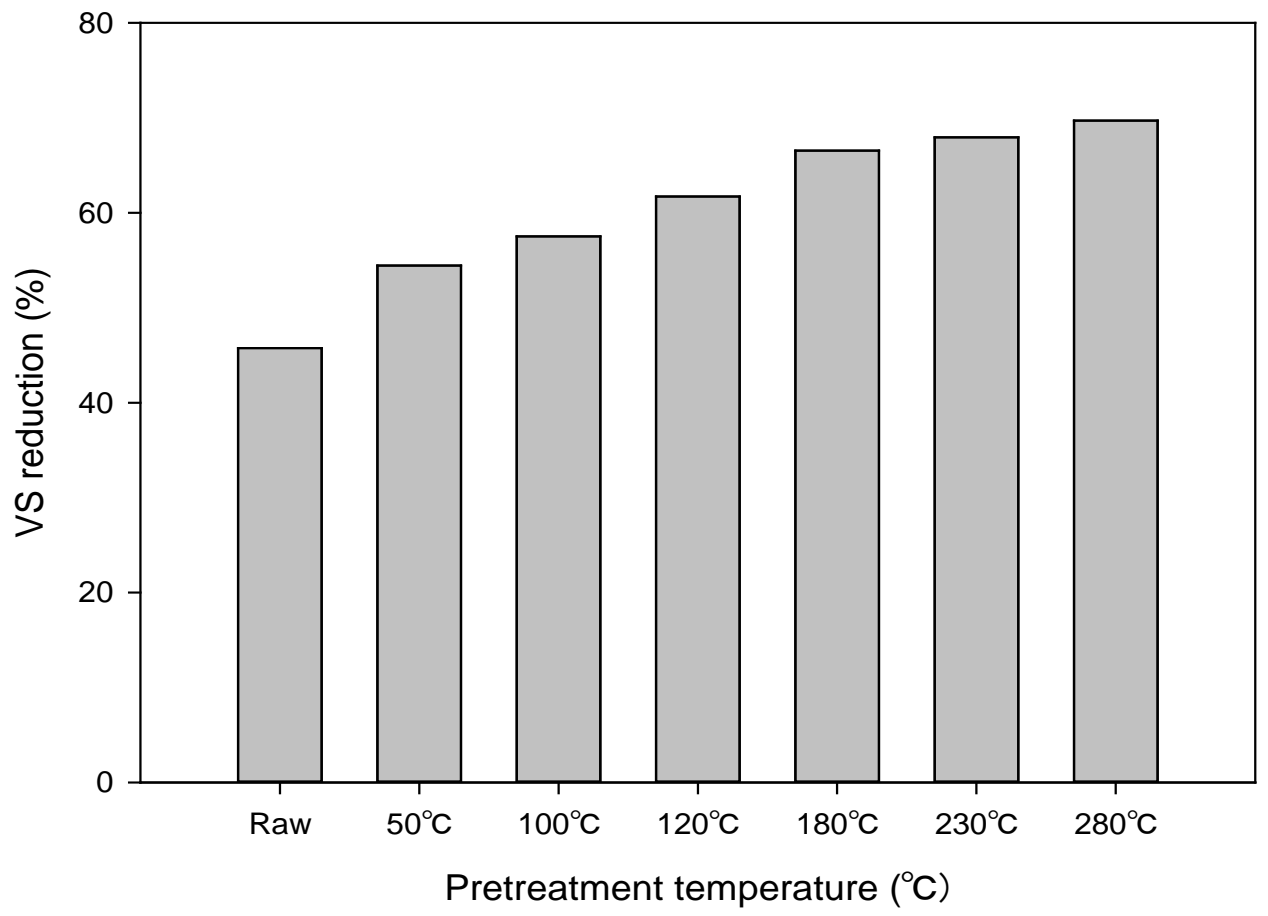

Figure 5. VS Reduction depend on the Pretreatment Temperatures at the End of Experiment

\section{Conclusion}

This study demonstrated that filamentous algal biomass, H. reticulatum, is a potential substrate at different $\mathrm{S} / \mathrm{I}$ ratio and thermal pretreatment for anaerobic digestion. In batch anaerobic digestion carried out at different S/I ratio, the ultimate methane production decreased from 163.6 to $105.8 \mathrm{~mL} / \mathrm{g}-\mathrm{VS}$ when the S/I ratio increased from 0.5 to 5.0. These results showed evident influence on methane production. The influence of thermal pretreatment depending on different temperatures were conducted 161.8, 169.1, 178.4, 191.7, 274.9, 285.2, and 364.4 $\mathrm{mL} / \mathrm{g}-\mathrm{VS}$ at raw, $50,100,120,180,230$, and $280^{\circ} \mathrm{C}$, respectively. The hydrothermal pretreatment was effective to improve methane production. The results of the VS reduction after anaerobic digestion batch test were achieved 45.8, 54.4, 57.5, 61.7, 
66.6, 68.0 and $69.7 \%$ with the applyed pretreatment temperatures at raw, 50, 100, $120,180,230$ and $280{ }^{\circ} \mathrm{C}$, respectively.

\section{Acknowledgments}

This research was supported by the main project "Development of Integrated Operation Technology on Construction Information \& Spatial Information based on BIM/GIS Interoperation Platform (Environment)" of Korea Institute of Civil Engineering and Building Technology (KICT).

\section{References}

[1] C. González-Fernández, B. Sialve, N. Bernet, and J.P Steyer, "Impact of microalgae characteristics on their conversion to biofuel. Part 2: Focus on biomethane production”, Biofuels, Bioprod. Biorefin., vol. 6, no. 2, (2011), pp. 205-218.

[2] C. González-Fernández, B. Sialve, N. Bernet, and J.P Steyer, “Thermal pretreatment to improve methane production of Scenedesmus biomass”, Biomass Bioenergy., vol. 40, (2012), pp. 105-111.

[3] A. Singh, and S. I. Olsen, "A critical review of biochemical conversion, sustainability and life cycle assessment of algal biofuels”, Appl. Energ. vol. 88, no. 10, (2011), pp. 3548-3555.

[4] O. Jorquera, A. Kiperstok, E.A. Sales, M. Embirucu, and M.L. Ghirardi, "Comparative energy life-cycle analyses of microalgal biomass production in open ponds and photobioreactors”, Bioresource Technol., vol. 101, no. 4, (2010), pp. 1406-1413.

[5] A. Guldhe, B. Signh, I. Rawat, K. Ramluckan, and F. Bux, "Efficacy of drying and cell disruption techniques on lipid recovery from microalgae for biodiesel production”, Fuel, vol. 128, (2014), pp. 4652.

[6] S. H. HO, S. W. Huang, C. Y. Chen, T. Hasunuma, A. Kondo, and J. S. Chang, "Bioethanol production using carbohydrate-rich microalgae biomass as feedstock”, Bioresource technol., vol. 135, (2013), pp. 191-198.

[7] L. D. Zhu, E. Hiltunen, E. Antila, J. J. Zhong, Z. H. Yuan, and Z. M. Wang, "Microalgae biofuels: Flexible bioenergies for sustainable development”, Renew. Sust. Energ. Rev., vol. 30, (2014), pp. 10351046.

[8] A. J. Ward, D. M. Lewis, and F. B. Green, “Anaerobic digestion of algae biomass : review”, Algal Res., vol. 5, (2014), pp. 204-214.

[9] K. Y. Park, J. Kweon, P. Chantrasakdakul, K. Lee, and H. Y. Cha, “Anaerobic digestion of microalgae biomass with ultrasonic disintegration”, Int. Biodeter. Biodegr., vol. 85, (2013), pp. 598-602.

[10] B. Sialve, N. Bernet, and O. Bernard, "Anaerobic digestion of microalgae as a necessary step to make microalgal biodiesel sustainable”, Biotechnol. Adv., vol. 27, no. 4, (2009), pp. 409-416.

[11] K. Lee, P. Chantrasakdakul, D. Kim, M. Kong, and K. Y. Park, "Ultrasound pretreatment of filamentous algal biomass for enhanced biogas production”, Waste Manage., vol. 34, no. 6, (2014), pp. 1035-1040.

[12] P. H. Chen, and W. J. Oswald, "Thermochemical treatment for algal fermentation", Environ. Int., vol. 24, no. 8, (1998), pp. 889-897.

[13] F. Passos, J. Garćia, and I. Ferrer, "Impact of low temperature pretreatment on the anaerobic digestion of microalgal biomass”, Bioresource Tehnol., vol. 138, (2013), pp. 79-86.

[14] C. G. Golueke, W. J. Oswald, and B. B. Gotaas, “Anaerobic digestion of algae”, Appl. Microbial., vol. 5, (1957), pp. 47-55.

[15] F. Passos, M. Solé, J. Garćia, and I. Ferrer, "Biogas production from microalgae grown in wastewater: Effect of microwave pretreatment”, Appl. Energ., vol. 108, (2013), pp. 168-175.

[16] C. González-Fernández, B. Sialve, N. Bernet, and J. P. Steryer, "Comparison of ultrasound and thermal pretreatment of Scenedesmus biomass on methane production”, Bioresource technol., vol. 110, (2012), pp. 610-616.

[17] P. Kumar, D.M. Barrett, and M. J. Delwiche, "Stroeve P., Methods for pretreatment of lignocellulosic biomass for efficient hydrolysis and biofuel production”, Ind. Eng. Chem. Res., vol. 48, no. 8, (2009), pp. 3713-3729.

[18] S. H. Mood, A. H. Golfeshan, M. Tabatabaei, G.S. Jouzani, G. H. Najafi, M. Gholami, and M. Ardjmand, "Lignocellulosic biomass to bioethanol, a comprehensive review with focus on pretreatment”, Renew. Sust. Energ. Rev., vol. 27, (2013), pp. 77-93.

[19] R. Chandra, H. Takeuchi, and T. Hasegawa, "Hydrothermal pretreatment of rice straw biomass: A potential and promising method for enhanced methane production”, Appl. Energy., vol. 94, (2012), pp. 129-140.

[20] I. Angelidaki, M. Alves, D. Bolzonella, L. Borzacconi, J. L. Campos, A. J. Guwy, P. Jenicek, and J. B. Van Lier, "Defining the biomethane potential (BMP) of solid organic wastes and energy crops: a proposed protocol for batch assay”, Water Sci. Technol., vol. 59, no. 5, (2009), pp. 927-934. 
[21] J. C. Young, and H. H. Tabak, "Multilevel protocol for assessing the fate and effect of toxic organic chemicals in anaerobic treatment processes”, Water Environ. Res., vol. 65, no. 1 (1993), pp. 34-45.

[22] APHA, "Standard methods for the examination of water and wastewater", 21ed. APHA, Washington, D.C., (2005).

[23] C. Eskicioglu, and M. Ghorbani, "Effect of inoculum/substrate ratio on mesophilic anaerobic digestion of bioethanol plant whole stillage in batch mode”, Process Biochem., vol. 46, no. 8, (2011), pp. 682-687.

[24] S. Zheng, X. Yuan, X. Shi, and Y. Qiu, "Effect of inoculum/substrate ratio on methane yield and orthophosphate release from anaerobic digestion of Microcystis spp. J. Hazard. Mater., vol. 178, no. 1-3, (2010), pp. 89-93.

[25] R. T. Haug, D. C. Stuckey, J. M. Gossett, and P. L. McCarty, "Effect of thermal pretreatment on digestibility and dewaterability of organic sludges”, J. Water Pollut. Control Fed., vol. 50, no. 1, (1978), pp. 73-85.

[26] P. Keymer, I. Ruffell, S. Pratt, and P. Lant, "High pressure thermal hydrolysis as pre-treatment to increase the methane yield during anaerobic digestion of microalgae”, Bioresource technol., vol. 131, (2013), pp. 128-133.

[27] C. A. Wilson, and J. T. Novak, "Hydrolysis of macromolecular components of primary and secondary wastewater sludge by thermal hydrolytic pretreatment”, Water Res., vol. 43, no.18, (2009), pp. 44894498.

[28] L. De schamphelaire, and W. Verstraete, "Revival of the biological sunlight-to-biogas energy conversion system”, Biotechnol. Bioeng., vol. 103, no. 2, (2009), pp. 296-304.

[29] D. Elango, M. Pulikesi, P. Baskaralingam, V. Ramamurthi, and S. Sivanesan, "Production of biogas from municipal solid waste with domestic sewage”, J. Hazard. Mater., vol. 141, no. 1, (2007), pp. 301304.

[30] C. Ratanatamskul, G. Onnum, and K. Yamamoto, "A prototype single-stage anaerobic digester for codigestion of food waste and sewage sludge from high-rise building for on-site biogas production”, Int. Biodeter. Biodegr., vol. 95 no. a, (2014), pp. 176-180.

\section{Authors}

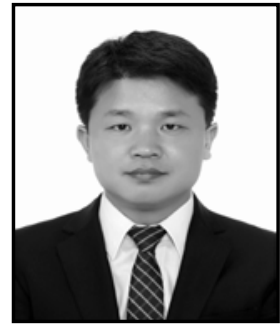

Kwanyong Lee, He graduated at Konkuk University $\mathrm{Ph}$. D in Civil and Environmental System Engineering. He graduated in February 2004 at Seoul National Unv. of Science and Technology, MS. in Environmental Enginnering. He graduated in February 2002 at Seoul National Unv. of Science and Technlogy in BS in Environmatial Engineering

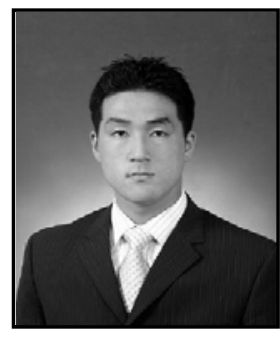

Daegi Kim, He graduate on December 2012 Ph. D Tokyo Institute Science and Technology. In March 2016 he is at the Institute for Advanced Engineering, Senior Researcher.

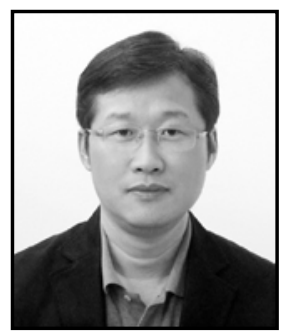

Ki Young Park, He graduated on February 1998, Ph. D, Seoul National University, Civil and he is a professor at Konkuk University. 


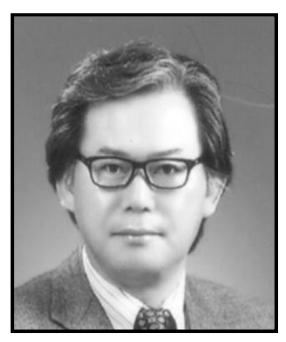

Hyundong Lee, He graduate at Kyoto University Post-Ph. D in Environmental Engineering, on Aug 1991 at Hanyang University he got his Ph. D in Civil and Environmental Engineering, on Feb 1987 at Hanyang University, he got his MS in Civil and Environmental Engineering.

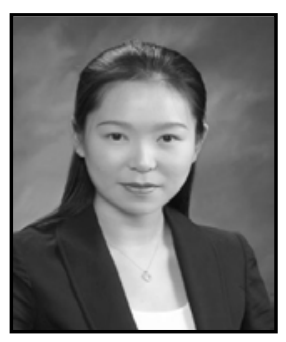

Chorong Kim, on Feb 2013 at Seoul National University, she got her MS in Civil and Environmental Engineering. On Feb 2007 at Sookmyung Women's University she graduated in BA in English Language and Literature. 